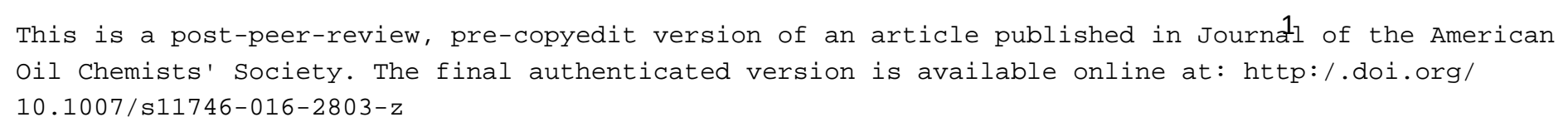

\title{
Bioactive compounds in virgin olive oil of the PDO Montoro-Adamuz
}

Romero, C., Ruiz-Méndez, Mª V., Brenes, M*

Instituto de la Grasa (IG-CSIC), Campus of University Pablo de Olavide, Edificio 46, Ctra. Utrera km 1, 41013-Seville, Spain

\author{
Corresponding author* \\ Name: Manuel Brenes \\ Telephone: +34954690850 \\ Fax: +34954691262 \\ E-mail: brenes@cica.es
}




\begin{abstract}
Virgin olive oil (VOO) is generally recognized as a healthy fat because of its fatty acid composition and content in minor compounds but a wide range of these substances can be found in commercial oils. The concentration of compounds with attributed health benefits were analyzed in VOOs of the PDO Montoro-Adamuz. Oleic acid represented around $79 \%$ of the total fatty acids, and the mean squalene and tocopherols concentrations were $5800 \mathrm{mg} / \mathrm{kg}$ and $247 \mathrm{mg} / \mathrm{kg}$ respectively. Despite the changes found in polyphenols concentration in the oils analyzed for six consecutive crops, these substances accounted for more than $700 \mathrm{mg} / \mathrm{kg}$. Moreover, the effect of irrigation regime and sun radiation on the content in bioactive substances of these oils was also assessed. No significant differences were detected between oils from trees irrigated ad libitum or rain-feed. In contrast, the level of tree radiation exerted a great effect on the concentration of bioactive substances in oils. Oils from trees cultivated in a sunny area (south orientation) had a higher percentage of oleic acid and concentration in phenolic compounds than those from shady areas (north orientation). The opposite was detected for tocopherols and squalene which were more concentrated in oils from olives of the shady area. The results obtained in this study point out VOOs of the PDO MontoroAdamuz as a very healthy fat due to their composition in bioactive substances, in particular their richness in phenolic compounds.
\end{abstract}

Keywords: olive oil, phenolic, oleic acid, squalene, tocopherols, Picual 


\section{Introduction}

The benefits of consuming olive oil have been known since antiquity and were traditionally attributed to its high content in oleic acid. However, olive oil possess a myriad of biologically active minor components such as tocopherols, sterols, squalene and particularly phenolic compounds that make this fat one of the healthiest among vegetable oils worldwide.

The positive effect of dietary monounsaturated fats in preventing cardiovascular diseases and cancer has extensively been reported [1,2], and claimed by international food and health agencies. The U.S. Food and Drug Administration has stated that the consumption of olive oil may reduce the risk of coronary heart disease due to its content in monounsaturated fat [3], and the European Food Safety Authority has reported that "replacing saturated fats in the diet with unsaturated fats contribute to the maintenance of normal blood cholesterol level" [4].

Sterols and squalene are other bioactive substances present in olive oil. Phytosterols or plant sterols can reduce intestinal absorption of cholesterol and subsequently serum cholesterol levels thereby they can contribute to prevention of myocardial infarction [5]. They have also been attributed with anticarcinogenic and antitumor properties [6].

Moreover, $\alpha$-tocopherol, which is the most common form of vitamin E, is the major tocopherol in olive oil, and it shows the highest antioxidant and biological activity among tocopherols and tocotrienols [7]. The EFSA has also indicated that vitamin E "contributes to the protection of cells from oxidative stress" [4].

Of particular interest from a nutritional point of view the phenolic compounds are. They comprise a high number of substances found at levels of $\mathrm{mg} / \mathrm{kg}$ oil but recognized with many nutritional activities because they exhibit protective effects against neurodegenerative and cardiovascular diseases [8]. Precisely, the European Commission has recently approved a health claim for olive oil polyphenols because of their contribution to the protection of LDL particles from oxidative damage [4].

There are many other minor substances in olive oil (carotenoids, aliphatic alcohols, triterpenic acids and others) although due to their low content in oil and/or low biological activity the scientific community has paid them less attention up to now. 
The chemical composition of virgin olive oil (VOO) is influenced by many variables like olive cultivar, agronomic and pedo-climatic conditions, fruit maturity and technological factors, among others. Consequently, VOO is not a uniform product but oils with a wide range in chemical composition and content in nutritional substances are commercialized. Hence, consumers are demanding VOO rich in these bioactive substances.

In the last few years, there has been increasing interest in the geographical characterization of VOO according to regulations on Protection Designation of Origin (PDO) and Protected Geographical Indication (PGI) [9]. These regulations are a guarantee of a precise geographical origin that determines sensory and chemical characteristics of oil but content in bioactive substances are not generally certified.

The VOO of the PDO Montoro-Adamuz is obtained from fruits of the Picual ( $>$ $90 \%)$ and Nevadillo negro $(<10 \%)$ olive cultivars which are harvested from orchards located in the province of Córdoba (Andalusia, Spain). The maximum acidity and peroxide value in this oil must be $0.5 \%$ and $20 \mathrm{mEq} . \mathrm{O}_{2} / \mathrm{kg}$ respectively but it is very appreciated by consumers because of its high content in phenolic compounds $(>700$ $\mathrm{mg} / \mathrm{kg}$ oil) [10]. However, no references can be found regarding the amount of these substances and others bioactive in the literature, particularly during several years. The chemical characterization of nutritional substances present in VOO of the PDO Montoro-Adamuz was studied for the first time.

The agricultural area with the denomination Montoro-Adamuz comprises mountainous orchards that suffer extreme Mediterranean climatic conditions, particularly shortage of water in summer and autumn. Hence, the main agronomic factors that can influence the content of these oils in bioactive substances are the irrigation regime and the orientation of the olive trees in the mountain, either in a shady or a sunny area.

\section{Materials and methods}

VOOs of the PDO Montoro-Adamuz 
Samples of oil were taken from industrial tanks by authorized personnel of the PDO, and sent to the laboratory for analysis without any stored period. These oils were collected from the season 2008/2009 to 2013/2014, and graded as extra virgin olive oils.

Effect of irrigation and sun radiation on bioactive compounds in oils

Olives were taken from trees located in the geographical area of the PDO MontoroAdamuz (Córdoba, Spain) during the season 2010/2011 (first fortnight of December). Fruits of the Picual and Nevadillo negro cultivars were harvested from trees irrigated $a d$ libitum or rain-feed only. All trees were cultivated in the same area by the same grower. Representative fruits ( $3 \mathrm{~kg}$ sample) at a maturity stage at which $50 \%$ of the fruits displayed black color on the surface, and the rest of them had yellow color were handpicked from 6 trees of each assay and brought to the laboratory for oil extraction the same day.

Fruits of both cultivars were also hand-picked from another different orchard from trees located in either a shady or a sunny area. In the northern hemisphere, the area of the mountain facing south receives more solar radiation than north. The olive trees were all rain-feed. These olives had a black surface color and they were collected from 12 trees of both the shady and the sunny area.

Oil extraction was performed using an Abencor laboratory oil mill (Comercial Abengoa SA, Spain) equipped with a hammer mill, a thermobeater, and a paste centrifuge. The extraction was carried out at $28{ }^{\circ} \mathrm{C}$ with kneading for $30 \mathrm{~min}$. The oily must was decanted and filtered before analysis. Extraction was run in duplicate.

Individual quantification of phenolic compounds in oils 
They were extracted from the oil with $N, N$-dimethylformamide (DMF) [11]. Briefly, 0.6 $\mathrm{g}$ of oil was extracted with $3 \times 0.6 \mathrm{~mL}$ of DMF; the extract was then washed with hexane, and $\mathrm{N}_{2}$ was bubbled into the DMF extract to eliminate residual hexane. Finally, the extract was filtered through a $0.22 \mu \mathrm{m}$ pore size nylon filter and injected into the chromatograph.

The chromatographic system consisted of a Waters 717 plus autosampler, a Waters 600 pump, and a Waters heater module (Waters Inc., Mildford, MA, USA). A Spherisorb ODS-2 (5 $\mu \mathrm{m}, 25 \mathrm{~cm}$ x $4.6 \mathrm{~mm}$ i.d., Waters Inc.) column was used. Separation was achieved using an elution gradient with an initial composition of $90 \%$ water ( $\mathrm{pH}$ adjusted to 3.0 with phosphoric acid) and $10 \%$ methanol [11]. The concentration of the latter solvent was increased to $30 \%$ over $10 \mathrm{~min}$ and maintained for $20 \mathrm{~min}$. Subsequently, the methanol percentage was raised to $40 \%$ over $10 \mathrm{~min}$, maintained for $5 \mathrm{~min}$, and then increased to $50 \%$. Finally, the methanol percentage was increased to 60,70 , and $100 \%$ in 5 min periods. Initial conditions were reached in 10 $\min$. A flow of $1 \mathrm{~mL} / \mathrm{min}$ and a temperature of $35^{\circ} \mathrm{C}$ were used in all of the analyses. A Waters 996 diode array detector and a Jasco FP-920 fluorescence detector (Jasco, Tokyo, Japan) were connected in series. Hydroxytyrosol, hydroxytyrosol glycol and tyrosol were purchased from Sigma-Aldrich (St. Louis, MO, USA), apigenin and luteolin from Extrasynthese (Genay, France), and the rest of standards were obtained by semipreparative HPLC following a similar conditions as described above [11].

Total contents of hydroxytyrosol and tyrosol in oils

They were analyzed following the method described elsewhere [12]. Olive oil (2.5 g) and $2 \mathrm{M} \mathrm{HCl}(50 \mathrm{~mL})$ were put into a $100 \mathrm{~mL}$ glass bottle that was closed with a polypropylene cap. The mixture was vigorously homogenized by agitation at $400 \mathrm{rpm}$ in an orbital shaking incubator model WY-200 for $5 \mathrm{~h}$ (Comecta SA, Barcelona, Spain). Experiments were run at $25{ }^{\circ} \mathrm{C}$. Finally, $2 \mathrm{~mL}$ of the aqueous phase was removed by a plastic pipet, filtered through a $0.22 \mu \mathrm{m}$ pore size nylon filter, and injected into the chromatograph. The chromatographic system was the same as noted above, except the gradient program of solvents that was modified, the washing period starting at $20 \mathrm{~min}$ 
from injection. Chromatograms were recorded at $280 \mathrm{~nm}$ and quantification was made using external calibration with standards (hydroxytyrosol and tyrosol) purchased from Sigma-Aldrich (St. Louis, MO, USA).

Squalene

Hydrocarbons were obtained by adsorption chromatography following the method described elsewhere [13]. GC was performed by using an Agilent 6890A chromatograph equipped with a cold on-column injector with oven-track system and a flame-ionization detector. A HP-5 column (5\% dipheny1/95\% dimethyl polysiloxane, length $15 \mathrm{~m}, 0.32 \mathrm{~mm}$ i.d. and $0.1 \mu \mathrm{m}$ film thickness; Agilent Tech.) was used. Hydrogen (140 kPa inlet pressure) was used as carrier gas and nitrogen as makeup gas. The oven temperature was held at $80^{\circ} \mathrm{C}$ for $5 \mathrm{~min}$ and then increased at $45^{\circ} \mathrm{C} / \mathrm{min}$ to $120^{\circ} \mathrm{C}$ and then at $5^{\circ} \mathrm{C} / \mathrm{min}$ to $310^{\circ} \mathrm{C}$ where it was held for $7 \mathrm{~min}$. The detector temperature was $350^{\circ} \mathrm{C}$. Concentration of hydrocarbons was obtained comparing the total area and the squalene internal standard area.

Tocopherols

They were determined by HPLC with fluorescence detection (excitation at $290 \mathrm{~nm}$ and emission at $330 \mathrm{~nm}$ ), following IUPAC Standard Method 2.432 [14]. The column was a Lichrosorb Si 60 packed with silica (5 $\mu \mathrm{m}$ particle size) (Merck, Darmstadt, Germany). The mobile phase was $n$-hexane/isopropanol $(99: 1, \mathrm{v} / \mathrm{v})$ with a flow rate of $1 \mathrm{~mL} / \mathrm{min}$.

Fatty acids and sterols

They were measured according to European Community Regulation 702/2007 [15]. 
Statistical analysis

Statistica software version 7.0 was used for data processing (Statistica for Windows, Tulsa, OK, USA). A comparison among mean variables was made by Duncan's multiple-range tests, and the differences were considered significant when $p<0.05$.

\section{Results and discussion}

Fatty acids

All the analyzed samples showed fatty acid content within the range required by European Regulation [15] (Table 1), being oleic acid the major fatty acid (ca. $79 \%$ ), which has been previously observed for VOO obtained from the Picual cultivar [16]. The EU regulation establishes a range for this monounsaturated acid between 55 and 83 $\%$ thereby the VOOs of the PDO Montoro-Adamuz are included close to the highest level.

Fig. 1 shows the effects of two agronomic factors on the content of oleic acid in these VOOs. First, it must be noted that oils obtained from olives of the Nevadillo negro cultivar had a lower percentage of oleic acid than those of the Picual cultivar. However, the percentage of Nevadillo negro oil into the total fat of VOO of the PDO MontoroAdamuz is lower than $10 \%$ [10]. Otherwise, oils from olives cultivated under nonirrigation trees presented a lower percentage of oleic acid for both cultivars Picual and Nevadillo negro, which is in agreement with previous studies [17]. It is known that reduced growth temperatures increase membrane lipid unsaturation in order to maintain membrane fluidity at low temperature, and several researchers have found higher percentage of oleic acid in oils obtained from cooler than warmer climate conditions of two different geographical areas [18]. In our study, oils from sunny areas trended to contain a higher percentage of oleic acid but it was not statistically significant (Fig. 1), thereby other agronomic conditions might influence to a large extent on the content of this fatty acid. 
Squalene

There are no limits for this bioactive substance in the international regulations on olive oil but this compound has been found in VOOs in a wide range from 800 to 12000 $\mathrm{mg} / \mathrm{kg}$ [13]. Squalene values for Greek oils have been recorded between 2000 and 6500 $\mathrm{mg} / \mathrm{kg}$ [19], and between 900 and $8700 \mathrm{mg} / \mathrm{kg}$ for Italian oils [20].

VOOs of the PDO Montoro-Adamuz showed a mean squalene concentration of $5800 \mathrm{mg} / \mathrm{kg}$, which is in accordance with previous data reported on Picual oils [21]. Like many other minor substances present in VOO, the concentration of squalene depends on olive cultivar, among other variables. The Nevadillo negro oils tended to possess a higher amount of this substance than those of the Picual cultivar (Fig. 2). Otherwise, the concentration of squalene was slightly influenced by the irrigation regime of the olive trees, which is in disagreement with a previous work [22] that found a consistently lower content of squalene in oils from trees receiving the lowest irrigation level. In contrast, the location of the olive tree in the same orchard had a great influence on the concentration of squalene in oils because both Picual and Nevadillo negro oils from fruit cultivated in the sunny area had a significant lower content than those from the shady area (Fig. 2). Several studies have shown that plants under environmental signals like high salinity, high UV-B levels and drought allocate squalene to produce triterpenes and sterols. Likewise, the content of squalene in both fruit and oil is influenced by olive maturation [23], which is currently affected by sun radiation. Hence, there are some interactions between sun radiation level and other agronomic factors that could affect the content of oils in squalene.

Tocopherols

As expected, $\alpha$-tocopherol was the major tocopherol in VOO of the PDO MontoroAdamuz, followed by $\gamma$-tocopherol (Table 1). The mean value of total tocopherols was $247 \mathrm{mg} / \mathrm{kg}$, which is in the average of the range previously reported for tocopherols in 
Spanish VOOs (84-463 mg/kg) [7], and in agreement with the content previously found in Picual VOOs [24]. It must be noted that the Nevadillo negro oils presented a higher concentration of these substances than the Picual (Fig. 3). Furthermore, no significant differences were observed in the concentration of tocopherols in VOOs due to the irrigation regime. By contrast, the oils from olives cultivated in the sunny areas had a low content in these substances than those obtained from the shady area irrespective of the cultivar. It is assumed that the tocopherols content in VOO decreases as ripening progress, it is cultivar dependent, and the rainfall level affects its concentration, increasing with water-stress [7]. However, no data are available on the effect of the sun radiation on olive trees during the year.

Sterols

A mean value of $1442 \mathrm{mg} / \mathrm{kg}$ oil was found for total sterols content in the VOOs of the PDO Montoro-Adamuz (Table 1), which is in accordance with data previously reported for oils obtained from fruits of the Picual cultivar [24]. This is a value higher than the minimum of $1000 \mathrm{mg} / \mathrm{kg}$ oil established for authenticity of VOOs by European legislation [15]. Although many factors can influence the content of VOOs in sterols, their concentration currently range between 1000 and $2000 \mathrm{mg} / \mathrm{kg}$, lower than data observed for other vegetable oils such as soybean, sunflower and rapeseed.

Phenolic compounds

There are many studies that report the composition of VOO as influenced by the growing area $[25,26]$, which has been mainly related to the rainfall level and altitude location of the olive trees. One of the main characteristics of the VOOs of the PDO Montoro-Adamuz is their high content in phenolic compounds, which must be higher than $700 \mathrm{mg} / \mathrm{kg}$ [10]. In Table 2, it is recorded the phenolic composition of these oils for the last six seasons. Previous works have reported the effect of the bearing cycle on the quality of olive oils [22] but few studies are available on the individual characterization of phenolic compounds in POD olive oils for many years. Obviously, there were 
differences among seasons but the total content was always higher than the limit of 700 $\mathrm{mg} / \mathrm{kg}$. Oils from the 2012/2013 season showed statistically higher concentration in total phenolic compounds than those of the 2008/2009, 2009/2010 and 201/2012 seasons, having those of the 2010/2011 and 2013/2014 season the lower statistical content. It must be noted that this is a very high concentration if it is compared with previous data from the literature [27]. In particular, these oils of Montoro-Adamuz are very rich in oleuropein and ligustroside aglycons (HyEA and TyEA), followed by the dialdehydic forms of decarboxymethyl elenolic acid linked to hydroxytyrosol (HyEDA) and tyrosol (TyEDA). The latter substance seems to be mainly responsible for the burning, pungent sensory notes in VOOs [28], and it did not reach a higher concentration of $140 \mathrm{mg} / \mathrm{kg}$ in VOOs of the Montoro-Adamuz, which could explain the non-extremely bitter sensation of these oils despite their high total phenolic content.

The phenolic profile of these oils also showed a significant presence of hydroxytyrosol, tyrosol, hydroxytyrosol acetylated, hydroxytyrosol glycol and, to a lesser extent, the flavonoids luteolin and apigenin. Because of the low content in the lignan 1-acetoxypinoresinol, the percentage of Picual oil in the Montoro-Adamuz oil must be high since this substance has been proposed as a biomarker of Picual oils [11]. Table 3 shows the phenolic profile of oils obtained from either Picual or Nevadillo negro fruit. It can be observed a big difference between these two oils, particularly the concentration of 1-acetoxypinoresinol was much lower in Picual oils than Nevadillo negro, whereas the opposite was found for the other lignan pinoresinol. These data corroborate the great contribution of the Picual cultivar to the characteristics of the oils of the PDO Montoro-Adamuz. Furthermore, the Nevadillo negro oil had a higher total phenolic content than the Picual oil, taking into consideration that all fruit were harvested in the same orchard.

Nevadillo negro oils were also richer in phenolic compounds irrespective of the irrigation regime or sun exposition level of the field. (Fig. 4). Likewise, total phenols were higher in oils from non-irrigated trees of the Nevadillo negro cultivar but the opposite behavior was found for the Picual cultivar. Previous works have shown that concentration of phenolic compounds decreases in VOO with increasing water irrigation of the olive trees [17, 29] but contradictory data has also been reported [30]. In fact, Moriana et al (2007) has proposed that the effect of irrigation on phenolic concentration 
takes place all year round and not just during the oil accumulation phase, which is the period when most growers irrigate their olive trees.

In our experiments, it was tested the effect of the sun exposition level of the olive trees on the phenolic content of the VOOs Montoro-Adamuz (Fig. 4). Both Picual and Nevadillo negro oils obtained from a sunny area exhibited higher phenolic concentration that those of the shady area. Olives grown at high altitude give rise to oils with high concentration in phenolic compounds [24], and this effect can be related to the climatic conditions but also with a higher heat accumulation. Hence, it is reasonable to find a high concentration of phenolic compounds in VOOs obtained from olives cultivated in sunny areas.

As well as the individual quantification of the main phenolic compounds of the oils, it was measured the total concentrations of both hydroxytyrosol and tyrosol following the method proposed recently by Romero and Brenes $(2012,2014)$. There is not an official method to analyze phenolic compounds in olive oil because of several drawbacks but this new method allows the reliable determination of the total concentration of the two most important simple phenolic compounds present in olive oil. The average contents of hydroxytyrosol and tyrosol in VOOs of the POD MontoroAdamuz during the seasons 2008-2013 were $184 \pm 60 \mathrm{mg} / \mathrm{kg}$ and $186 \pm 47 \mathrm{mg} / \mathrm{kg}$ respectively. These data are higher than most of those reported for many commercial Spanish VOOs [12], and they confirm the richness of these oils in these bioactive substances.

\section{Conclusions}

Many variables contribute to the concentration of phenolic compounds in VOOs such as cultivar, agronomic conditions, technological processing, irrigation and others. In the case of the VOOs of the POD Montoro-Adamuz, it has been attributed to (i) the presence of the Nevadillo negro cultivar in the coupage of these oils, (ii) the extreme agro-climatic conditions which cause physiological stress in the olive tree, and (iii) the early harvesting of the fruit [10].

The results obtained in this work indicate that VOOs of the POD MontoroAdamuz are very rich in bioactive substances. They contain a high content in oleic acid, 
squalene, sterols and tocopherols but they are particularly rich in phenolic compounds, being their concentration higher than $700 \mathrm{mg} / \mathrm{kg}$ during the last six crop seasons. Besides, their total contents of hydroxytyrosol and tyrosol was higher than reported for many other VOOs. The irrigation regime studied did not show a significant effect on the content of bioactive substances in these oils. By contrast, the level of sun radiation on olive trees exerted a great influence on the concentration of these substances. Oils from trees cultivated in a sunny area had a higher percentage of oleic acid and concentration in phenolic compounds than those from shady areas. The opposite was detected for tocopherols and squalene which were more concentrated in oils from olives of the shady area. These results could contribute to make blended oils with specific content in bioactive substances.

\section{Acknowledgments}

The authors are grateful to Irene de la Rosa for technical help. The authors also thank Antonio Terán and PDO Montoro-Adamuz for providing samples and support. 


\section{References}

1. Carrillo, C, Cavia, MD, Alonso-Torre, SR (2012) Antitumor effect of oleic cid; mechanisms of action; a review. Nutr Hosp 27:1860-1865

2. Varela, LM, Ortega-Gomez, A, Lopez, S, Abia, R, Muriana, FJ, Bermudez, B (2013) The effects of dietary fatty acid on the postpandrial triglyceride-rich lipoprotein/apoB48 receptor axis in human monocyte/macrophage cells. J Nutr Biochem 24:2031-2039

3. FDA (Food and Drug Administration, USA) (2004) Docket No. 2003Q-0559. Monounsaturated fatty acids from olive oil and coronary heart disease

4. EC (European Commission) (2012) Regulation No 432/2012 establishing a list of permitted health claims made on foods. Off J Eur Union L/136/1

5. Klingberg, S, Ellegard, L, Johansson, I, Jansson, JH, Hallmans, G, Winkvist, A (2013) Dietary intake of naturally occurring plant sterols is related to a lower risk of a first myocardial infarction in men but not in women in Northern Sweden. J Nutr 143:1630-1635

6. Spanova, M, Daum, G (2011) Squalene-biochemistry, molecular biology, process biotechnology, and applications. Eur J Lipid Sci Technol 113:12991320

7. Beltrán, G, Jiménez, A, del Rio, C, Sánchez, S, Martínez, L., Uceda, M, Aguilera, MP (2010) Variability of vitamin E in virgin olive oil by agronomical and genetic factors. J Food Comp Anal 23:633-639

8. Frankel, EN (2011) Nutritional and biological properties of extra virgin olive oil. J Agric Food Chem 59:785-792

9. García-González, DL, Tena, N, Aparicio, R (2012) Describing the chemical singularity of the Spanish protected designations of origin for virgin olive oils in relation to oils from neighbouring areas. Grasas Aceites 63:26-34 
10. EC (European Commission) (2010). Publication of an applicant pursuant to Article 6 (2) of Council Regulation (EC) No 510/2006 on the protection of geographical indications and designations of origin for agricultural products and foodstuffs. Off J Eur Union C 125/19

11. García, A, Brenes, M, Romero, C, García, P, Garrido, A (2002) Use of 1acetoxypinoresinol to authenticate Picual olive oils. Int J Food Sci Technol $37: 615-625$

12. Romero, C, Brenes, M (2012) Analysis of total contents of hydroxytyrosol and tyrosol in olive oils. J Agric Food Chem 60:9017-9022

13. Lanzón, A, Albi, T, Cert, A, Gracián, J (1994) The hydrocarbon fraction of virgin olive oil and changes resulting from refining. J Am Oil Chem Soc 71:285292

14. IUPAC (International Union of Pure and Applied Chemistry) (1992) Standards Methods for the Analysis of Oils, Fats and Derivatives. $1^{\text {st }}$ Suppl. to $7^{\text {th }}$ Edn., Pergamon Press, Oxford, UK

15. EC (European Commission) (2007). Regulation EC/702/2007 amending Regulation EEC/2568/91 on the characteristics of olive oil and olive-residue oil and on the relevant methods of analysis. Off J Eur Union L-161/11-27

16. Beltrán, G, del Rio, C, Sánchez, S, Martínez, L (2004) Influence of harvest date and crop yield on the fatty acid composition of virgin olive oils from cv. Picual. J Agric Food Chem 52:3434-3440

17. Stefanoudaki, E, Williams, M, Chartzoulakis, K, Harwood, J (2009) Effect of irrigation on quality attributes of olive oil. J Agric Food Chem 57:7408-7055

18. Piravi-Vanak, Z, Ghasemi, JB, Ghavami, M, Ezzatpanah, H, Zolfonoun, E (2012) The influence of growing region on fatty acids and sterol composition of Iranian olive oils by unsupervised clustering methods. J Am Oil Chem Soc $89: 371-378$

19. Nenadis, N, Tsimidou, MZ (2002) Determination of squalene in olive oil using fractional crystalization for simple preparation. J Am Oil Chem Soc 79:257-259 
20. De Leonardis, A, Macciola, V, De Felice, M (1998) Rapid determination of squalene in virgin olive oils using gas-liquid chromatography. Ital J Food Sci $10: 75-80$

21. Samaniego-Sánchez, C, Quesada-Granados, JJ, López-García de la Serrana, H, López-Martínez, MC (2010) ß-Carotene, squalene and waxes determined by chormatography method in picual extra virgin olive oil obtained by a new cold extraction system. J Food Comp Anal 23:671-676

22. Ben-Gal, A, Dag, A, Basheer, L, Yermiyahu, U, Zipori, I, Kerem, Z (2011) The influence of bearing cycles on olive oil quality response to irrigation. J Agric Food Chem 59:11667-11675

23. Fernández-Cuesta, A, León, L, Velasco, L, De la Rosa, R (2013) Changes in squalene and sterols associated with olive maturation. Food Res 54:1885-1889

24. Aparicio, R, Luna, G (2002) Characterization of monovarietal virgin olive oils. Eur J Lipid Sci Technol 104:614-627

25. Di Vaio, C, Nocerino, S, Paduano, A, Sacchi, R (2013) Influence of some environmental factors on drupe maturation and olive oil composition. J Sci Food Agric 93:1134-1139

26. Kesen, S, Kelebek, H, Selli, S (2014) LC-ESI-MS characterization of phenolic profiles Turkish olive oils as influenced by geographic origin and harvest year. $\mathrm{J}$ Am Oil Chem Soc 91:385-394

27. García, A, Brenes, M, García, P, Romero, C, Garrido, A (2003) Phenolic content in commercial olive oils. Eur Food Res Technol 216:520-525

28. Andrewes, P, Busch, JLHC, Joode, T, Groenewegen, A, Alexandre, H (2003) Sensory properties of virgin olive oil polyphenols: identification of deacetoxyligstroside aglycon as a key contributor to pungency. J Agric Food Chem $51: 1415-1420$

29. Tovar, MJ, Motilva, MJ, Luna, M, Girona, J, Romero, M P (2001) Analytica characteristics of virgin olive oil from young trees (Arbequina cultivar) growing under linear irrigation strategies. J Am Oil Chem Soc 78:843-849 
30. Servili, M, Selvaggini, R, Esposto, S, Taticchi, A, Montedoro, G F, Morozzi, G (2004) Health and sensory properties of virgin olive oil hydrophylic phenols: agronomic and technological aspects of production that affect their occurrence in the oil. J Chromatogr 1054:113-127

31. Moriana, A, Pérez-López, D, Gómez-Rico, A, Salvador, M, Olmedilla, N, Ribas, F, Fregapane, G (2007) Irrigation scheduling for traditional, low-density olive orchard: water relations and influence on oil characteristics. Agric Water Manage 8:71-179 
Figure legends

Fig. 1. Influence of agronomic conditions on the content in oleic acid of oils obtained at laboratory scale of the Picual and Nevadillo negro cultivar. Bars mean the standard deviation of two samples. Different letters mean significant differences according to a Duncan's multiple range test $(P<0.05)$.

Fig. 2. Influence of agronomic conditions on the content in squalene of oils obtained at laboratory scale of the Picual and Nevadillo negro cultivar. Bars mean the standard deviation of two samples. Different letters mean significant differences according to a Duncan's multiple range test $(P<0.05)$.

Fig. 3. Influence of agronomic conditions on the content in tocopherols of oils obtained at laboratory scale of the Picual and Nevadillo negro cultivar. Bars mean the standard deviation of two samples. Different letters mean significant differences according to a Duncan's multiple range test $(P<0.05)$.

Fig. 4. Influence of agronomic conditions on the content in phenolic compounds of oils obtained at laboratory scale of the Picual and Nevadillo negro cultivar. Bars mean the standard deviation of two samples. Different letters mean significant differences according to a Duncan's multiple range test $(P<0.05)$. 
Table 1 Fatty acid and sterol composition, squalene and tocopherols contents in virgin olive oils of the PDO Montoro-Adamuz obtained during the season 2009/2010.

\begin{tabular}{|c|c|}
\hline & Mean (standard deviation) ${ }^{\mathrm{a}}$ \\
\hline \multicolumn{2}{|l|}{ Fatty acids $(\%)$} \\
\hline Palmitic acid $C_{16: 0}$ & $10.74(1.21)$ \\
\hline Palmitoleic acid $C_{16: 1}$ & $0.77(0.11)$ \\
\hline Stearic acid $C_{18: 0}$ & $2.81(0.26)$ \\
\hline Oleic acid $C_{18: 1}$ & $79.04(0.99)$ \\
\hline Linoleic acid $C_{18: 2}$ & $4.56(0.48)$ \\
\hline Linolenic acid $C_{18: 3}$ & $0.58(0.02)$ \\
\hline Arachidic acid $C_{20: 0}$ & $0.30(0.06)$ \\
\hline Eicosenoic acid $C_{20: 1}$ & $0.21(0.03)$ \\
\hline Behenic acid $C_{22: 0}$ & $0.07(0.02)$ \\
\hline Squalene (mg/kg) & $5843(779)$ \\
\hline \multicolumn{2}{|l|}{ Tocopherols (mg/kg) } \\
\hline$\alpha$-Tocopherol & $213(41)$ \\
\hline$\gamma$-Tocopherol & $34(5)$ \\
\hline Total tocopherols & $247(43)$ \\
\hline Total sterols (mg/kg) & $1442(122)$ \\
\hline Apparent $\beta$-sitosterol (\%) & $96.55(1.80)$ \\
\hline Campesterol (\%) & $2.00(0.18)$ \\
\hline Stigmasterol (\%) & $1.46(1.80)$ \\
\hline
\end{tabular}

${ }^{a}$ Each value is the mean of 29 replications. 
Table 2 Concentration of phenolic compounds in virgin olive oils of the PDO Montoro-Adamuz during several seasons.

\begin{tabular}{|c|c|c|c|c|c|c|}
\hline Compound $(\mathrm{mg} / \mathrm{kg})$ & $08 / 09^{a}$ & $09 / 10$ & $10 / 11$ & $11 / 12$ & $12 / 13$ & $13 / 14$ \\
\hline Hy-Glycol ${ }^{b}$ & $11(10)^{\mathrm{c}}$ & $10(8)$ & 7 (4) & $11(1)$ & $6(2)$ & $4(1)$ \\
\hline Hydroxytyrosol & $40(15)$ & $34(16)$ & $13(9)$ & $17(1)$ & $18(8)$ & $9(16)$ \\
\hline Tyrosol & $12(5)$ & $13(6)$ & $8(3)$ & $7(1)$ & $9(4)$ & $6(5)$ \\
\hline HyAC & $17(7)$ & $20(7)$ & $17(11)$ & $21(5)$ & $12(5)$ & $7(3)$ \\
\hline HyEDA & $154(71)$ & $164(79)$ & $102(57)$ & $195(15)$ & $232(75)$ & $129(35)$ \\
\hline TyEDA & $101(31)$ & $110(42)$ & $76(24)$ & $100(16)$ & $138(36)$ & $135(30)$ \\
\hline HyEA & $289(64)$ & $283(93)$ & $230(63)$ & $272(5)$ & $434(125)$ & $189(45)$ \\
\hline TyEA & $463(110)$ & $348(98)$ & $244(70)$ & $267(2)$ & $472(160)$ & $281(43)$ \\
\hline 1-Acetoxypinoresinol & $11(5)$ & $7(6)$ & $9(7)$ & $5(3)$ & $5(4)$ & $7(5)$ \\
\hline Pinoresinol & $44(6)$ & $367)$ & $45(13)$ & $45(3)$ & $40(8)$ & $36(7)$ \\
\hline Luteolin & $1(1)$ & $4(1)$ & $4(1)$ & $3(0)$ & $4(1)$ & $2(1)$ \\
\hline Apigenin & $<1$ & $1(0)$ & $1(1)$ & $<1$ & $1(0)$ & $<1$ \\
\hline TOTAL & $1143(212)$ & $1030(271)$ & $756(202)$ & $943(5)$ & $1371(354)$ & 806 (137) \\
\hline
\end{tabular}

${ }^{a}$ The number of samples analyzed during the seasons 08/09, 09/10, 10/11, 11/12, 12/13 and 13/14 were 19, 29, 28, 3, 14 and 13 respectively.

${ }^{\mathrm{b}} \mathrm{Hy}-\mathrm{Glycol}$, hydroxytyrosol glycol; HyAC, hydroxytyrosol acetylated; HyEDA, dialdehydic form of decarboxymethyl elenolic acid linked to 


\section{Page 21 of 26}

Journal of the American Oil Chemists

hydroxytyrosol; TyEDA, dialdehydic form of decarboxymethyl elenolic acid linked to tyrosol; HyEA, oleuropein aglycon; TyEA, ligustroside aglycon. ${ }^{\mathrm{c}}$ Standard deviation is shown between parenthesis. 
Table 3 Concentration of phenolic compounds $(\mathrm{mg} / \mathrm{kg})$ in virgin olive oils obtained from the Picual and Nevadillo negro olive varieties at laboratory scale. Fruits were cultivated in the same orchard and trees were not irrigated. Values are the mean of duplicates.

\begin{tabular}{|c|c|c|}
\hline Compound & Picual & Nevadillo negro \\
\hline Hy-Glycol & $1(0)^{\mathrm{a}}$ & $1(0)$ \\
\hline Hydroxytyrosol & $3(1)$ & $5(1)$ \\
\hline Tyrosol & $3(1)$ & $10(2)$ \\
\hline HyAC & $50(6)$ & $31(4)$ \\
\hline HyEDA & $196(31)$ & $327(50)$ \\
\hline TyEDA & $41(6)$ & $154(21)$ \\
\hline HyEA & $260(55)$ & $322(61)$ \\
\hline TyEA & $176(41)$ & $345(37)$ \\
\hline Luteolin & $8(1)$ & $7(1)$ \\
\hline Apigenin & $1(0)$ & $2(0)$ \\
\hline 1-Acetoxypinoresinol & $2(0)$ & $51(2)$ \\
\hline Pinoresinol & $50(3)$ & $8(1)$ \\
\hline Total & $791(124)$ & $1263(106)$ \\
\hline
\end{tabular}

${ }^{\text {a }}$ Standard deviation is shown between parenthesis. See Table 2 for compounds identification 
圆Picual $\square$ Nevadillo negro
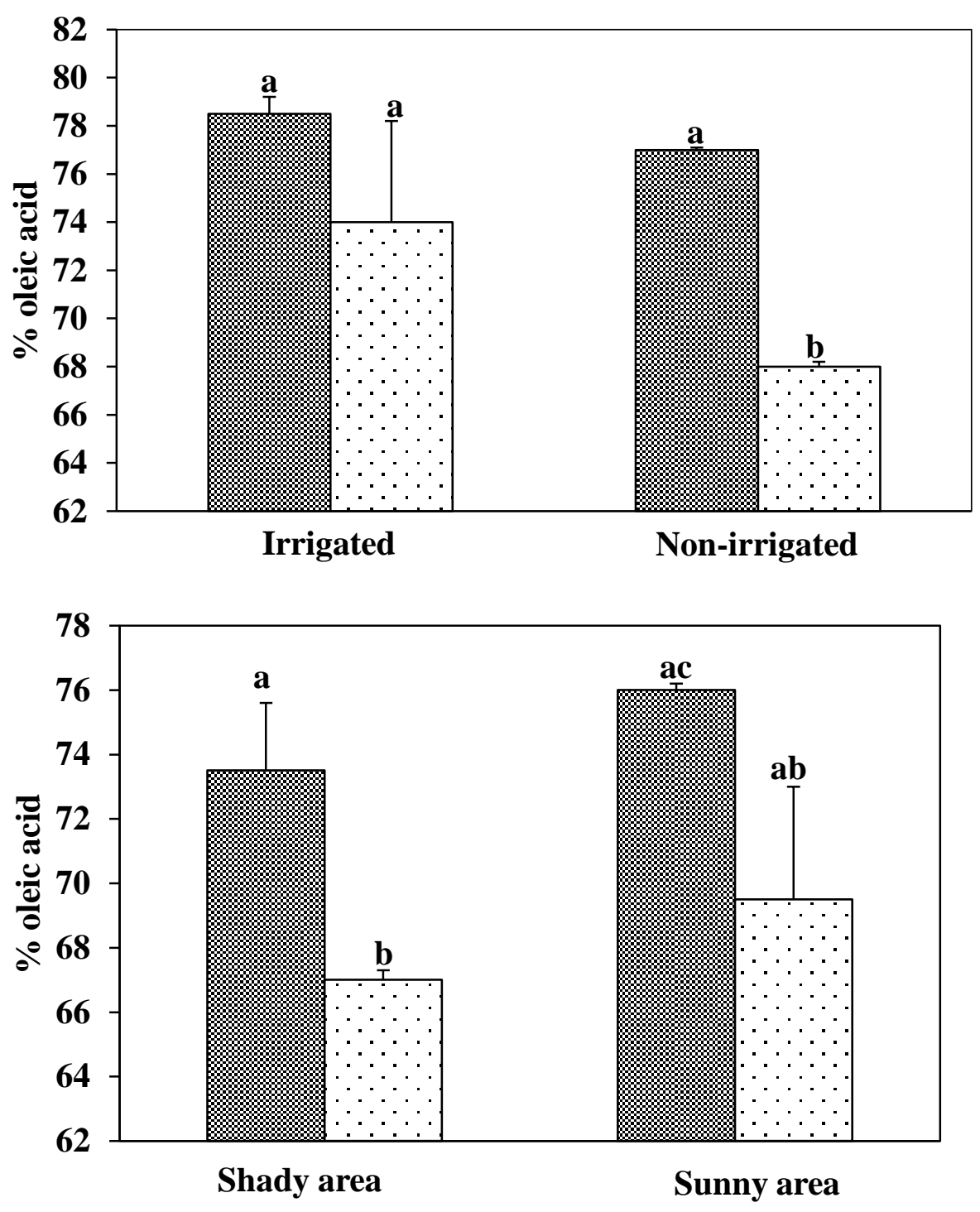
$\square$ Picual $\square$ Nevadillo negro
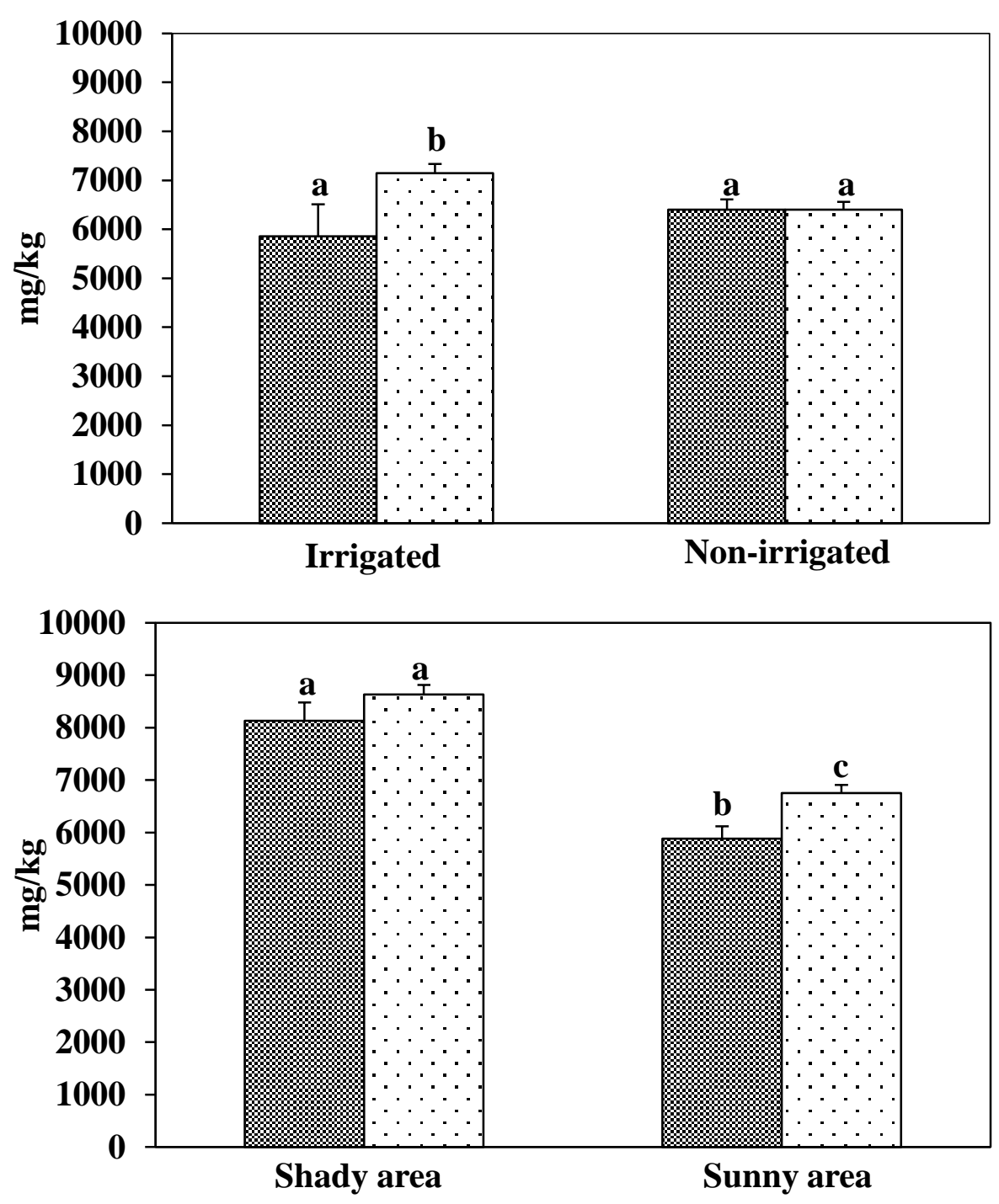

Figure 2 
圆Picual $\square$ Nevadillo negro
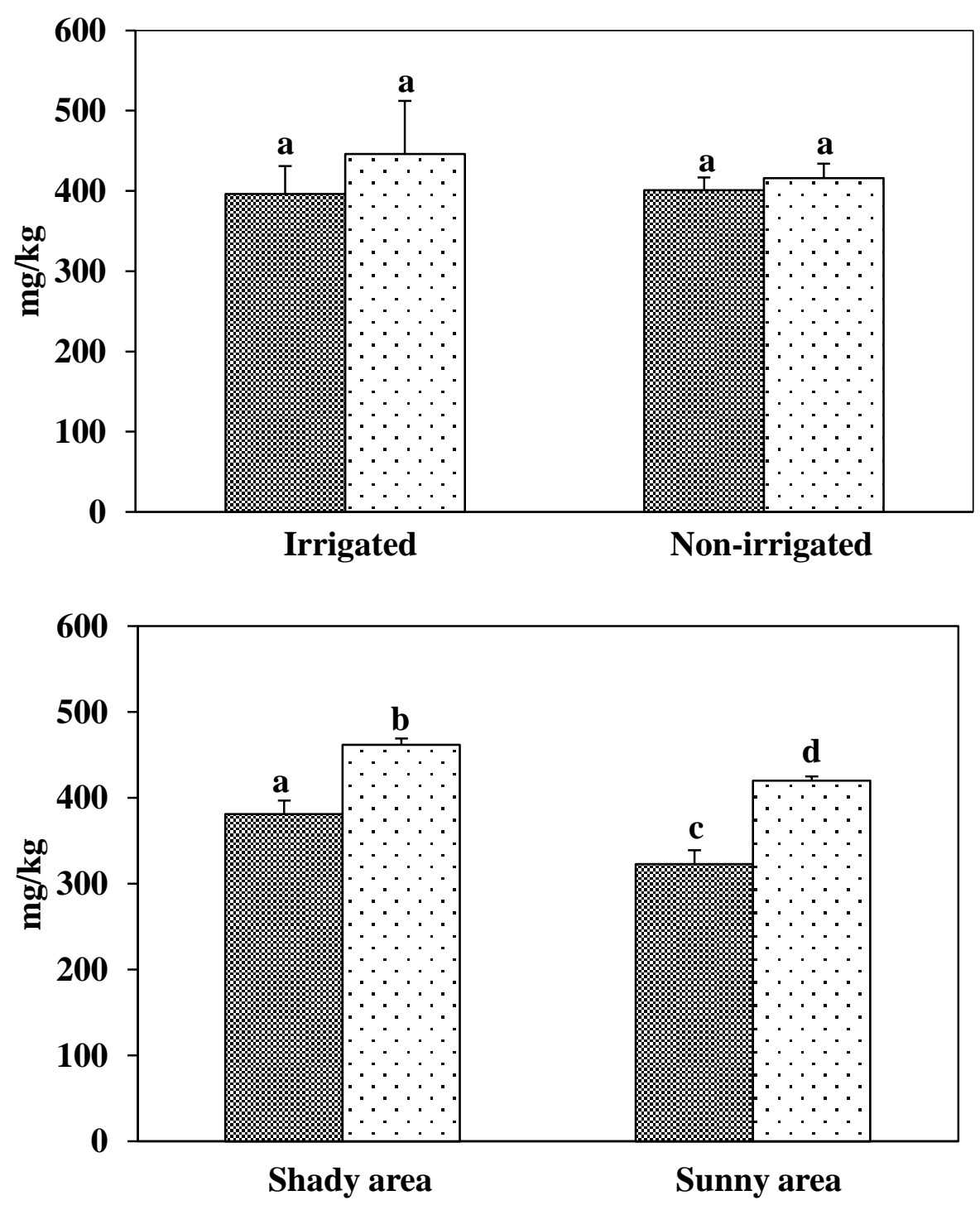

Figure 3 
圆Picual $\square$ Nevadillo negro
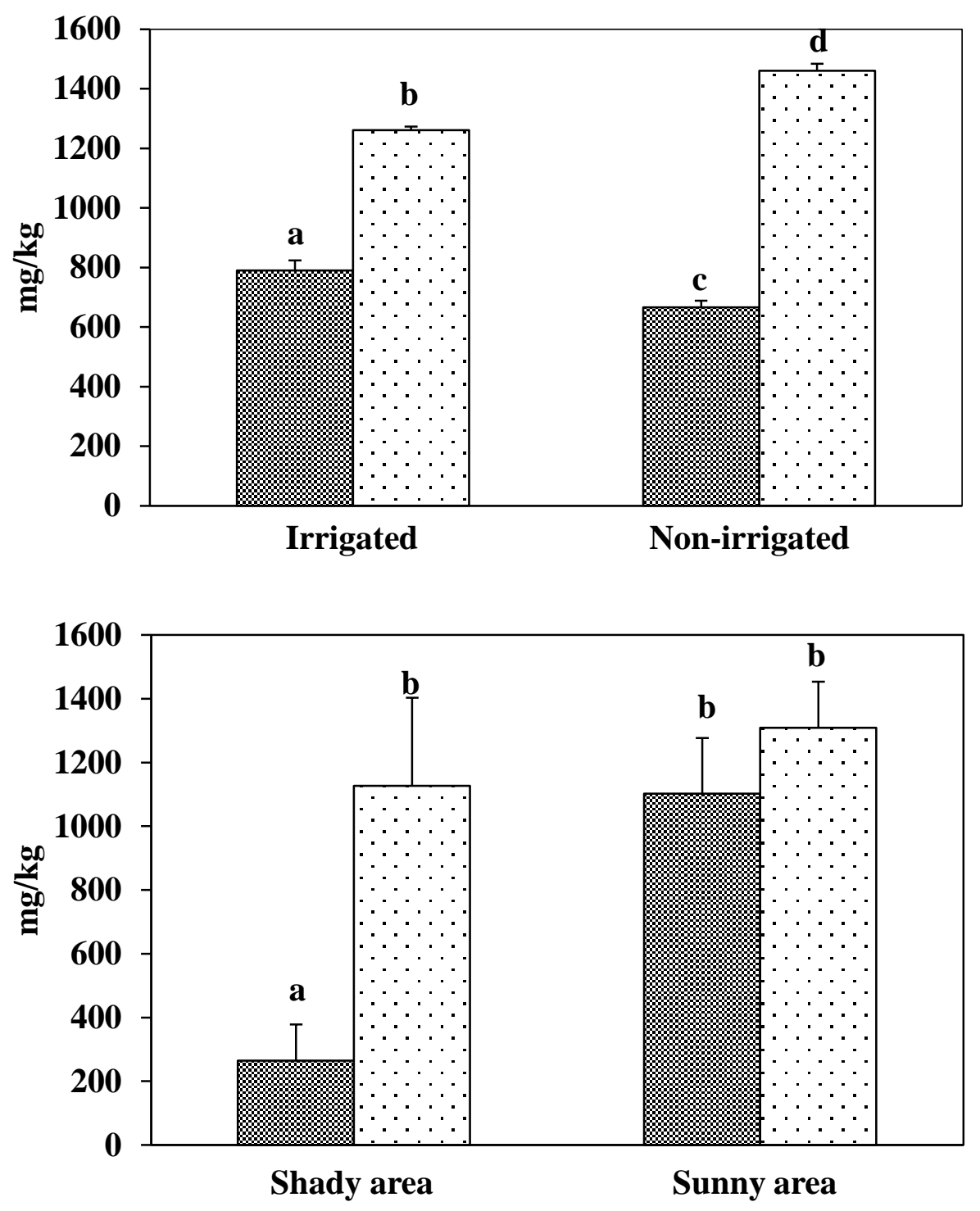

Figure 4 